\title{
Body Irradiation Model
}

National Cancer Institute

\section{Source}

National Cancer Institute. Body Irradiation Model. NCI Thesaurus. Code C161499.

A description of the area or extent of the body that is exposed to radiation. This may include information about the body part that is irradiated as well as procedures that may be done in conjunction with the radiation. 